\title{
Relationship between Calcium Deposit Size with the Pain Intensity in Patients with Calcified Rotator Cuff Tendinitis
}

\author{
Indri Wijayanti, I Nyoman Murdana, Tirza Z. Tamin
}

Departement of Physical Medicine and Rehabilitation, University of Indonesia / Cipto Mangunkusumo National Hospital, Jakarta, Indonesia.

ABSTRACT
Background: Calcified tendinitis is a disease characterized by calcification of multifocal cells mediated by
living tissue. Calcified tendinitis may occur due to the collection of calcium in the supraspinatus tendon pouch
or may be spread between rotator cuff muscle fibers and bursa, it may not cause pain or may cause mild pain
or discomfort. The aim is to determine the correlation of calcium deposit size to the pain intensity in patients
with calcified tendinitis.
Methods: Methods in this study was a cross-sectional study, twenty subjects, aged 50-70 years old, diagnosed
with calcified tendinitis rotator cuff through musculoskeletal ultrasonography examination.
Results: No significant correlations were found between calcium deposit size and pain intensity using VAS,
r=0.238, p=0.312.
Conclusion. The size of the calcium deposit was not correlated with the pain intensity in rotator cuff calcified
tendinitis patients. But further research is needed whether the location and form of calcium deposits affect the
pain intensity in calcified tendinitis rotator cuff patients.
Keywords: calcified tendinitis; calcium deposit size; pain intensity.

\section{Correspondence Detail:}

Indri Wijayanti.

Email : indriwijayanti@yahoo.com

Department of Physical Medicine and Rehabilitation,

University of Indonesia/Cipto Mangunkusumo National Hospital

Jalan Pangeran Diponegoro No.71, Jakarta Pusat, DKI Jakarta, Indonesia. 


\section{INTRODUCTION}

Calcified tendinitis is a disease characterized by calcification of multifocal cells mediated by living tissue. ${ }^{1}$ Calcified tendinitis may occur due to the accumulation of calcium in the supraspinatus tendon pouch or may be spread between rotator cuff muscle fibers and bursa. Calcific tendinitis may found on subjects more than 40 years old, usually occurs during the fifth and sixth decades of life. It occurs within the supraspinatus tendon in almost $50 \%$ of cases. It is more common in females $(60 \%)$. It occurs more commonly with sedentary workers than with heavy labor workers $(45 \%$ are house wives). ${ }^{2}$ During the acute resorbtive phase the calcium deposits shows increase vascularization with macrophage and mononuclear giant cell infiltration together with fibroblast formation, produces an aggressive inflammatory cell accumulation. There are excessive edema and rise of the intra-tendineous pressure. This leads to severe pain which is attributed by some to secondary impingement resulting from the increased tendon size, or due to rupture of the deposits into the subacromial space or bursa. ${ }^{2}$

Calcified tendinitis characterized with pain in the anterolateral arm, which does not exceed the elbow. There is pain especially at night and weakness during movement of shoulder. Most patients complain of chronic pain, and few with acute or sub acute pain on overuse and stretching shoulders. ${ }^{4}$ The shoulder pain may limit daily activity, increase dependency, and finally may reduce the quality of life. Early diagnosis is necessary to prevent further decline of shoulder function. There is still limitation of evidence in Indonesia, how to diagnose by analyze shoulder pain by physical examination, and consider about the size of calcification on rotator cuff by ultrasound finding. Measurement of pain is using Visual Analog Scale (VAS), which is subjectively measure pain intensity by patients scale of perceived. ${ }^{5}$ The aim of this study to found the correlation between the size of calcium deposit with the pain intensity on individu with calcified tenditis of rotator cuff.

\section{METHODS}

\section{Study Design, Place and Participants}

This study was a cross-sectional study, conducted in outpatient clinic of Medical Rehabilitation Department of Cipto Mangunkusumo Hospital, Jakarta, Indonesia. Twenty subjects, aged 50-70 years old, diagnosed with calcified tendinitis rotator cuff through musculoskeletal ultrasonography examination. Inclusion criteria include: pain with $\mathrm{VAS} \geq 4$, willing to participate in this study and sign the informed consent. Subjects were excluded if diagnosed with infection and malignancy that caused shoulder pain, shoulder rheumatoid or osteoarthritis, partial or total tear of rotator cuff and not cooperative.

\section{Measurements}

Calcium deposit size measured with musculoskeletal ultrasonography examination (in $\mathrm{mm}$ ). Pain intensity assess with visual analogue scale (VAS). Visual analogue scale 
is an subjective assessment to evaluate pain intensity. VAS has 0 to 10 scales, with number 0 means no pain, 1-3 means mild pain intensity, 4-6 means moderate pain intensity and 7-10 means severe pain intensity.

\section{Statistical Analysis}

All data will be presented in tables and statistical analysis was done using Statistical Product and Service Solution (SPSS) v.18 for windows. Kolmogorov-Smirnov test was used to evaluate normality of data distribution. Spearman and Pearson correlation coefficients were applied to assess relationship between variables.

\section{RESULTS}

\section{Clinical characteristic of subjects}

The study population consisted of $55 \%$ $(n=11)$ females and $45 \%(n=9)$ males calcified tendinitis rotator cuff patients. Their median age was 62.00 (55-70) years old. Right shoulder $(65 \%)$ more than left shoulder (35\%). Calcium deposit dominantly found at supraspinatus $(65 \%)$, followed by subscapularis (25\%), then infraspinatus $(10 \%)$. Single calcification dominant than multiplecalcification(65\%:35\%). Onset of pain was 4.50 (3-6) month. Mean of calcification size is $4.93( \pm 1,86) \mathrm{mm}$. Mean of pain intensity (VAS) $57.00( \pm 10.25) \mathrm{mm}$. This clinical characteristic of subjects can be seen at table 1 .

\section{Table 1. Clinical characteristic of subjects}

\begin{tabular}{lc} 
Characteristic & Statistical analysis \\
\hline Age(year) & $62.00(55-70)$ \\
Gender & \\
Female & $55 \%$ \\
Male & $45 \%$ \\
Shoulder & \\
Right & $65 \%$ \\
Left & $35 \%$ \\
Location & \\
Supraspinatus & $65 \%$ \\
Infraspinatus & $10 \%$ \\
Subscapularis & $25 \%$ \\
Calcification & \\
Single & $65 \%$ \\
Multiple & $35 \%$ \\
Onset (Month) & $4,50(3-6)$ \\
Calcification size & $4,93( \pm 1.86)$ \\
VAS score & $57.00( \pm 10.25)$ \\
\hline
\end{tabular}


Table 2. Correlation between calcium deposit size and pain intensity

\begin{tabular}{ccc} 
Variable & $\mathrm{r}$ & $\mathrm{P}$ Value \\
\hline Caccium deposit size & & \\
Pain intensity (VAS) & $-0,238$ & 0,312
\end{tabular}

No significant correlations were found between calcium deposit size and pain intensity

\section{DISCUSSION}

The prevalence of tendinitis calcified rotator cuff is $2-20 \%$ in asymptomatic (no pain) rotator cuff disorder, whereas in patients with rotator cuff pain, prevalence is reported to be $50 \%$. Most often about the age of 30-60 years. There was no correlation of the incidence of the disease with heavy work or exercise with shoulder joint movement overhead in the dominant upper extremity. ${ }^{1,2}$ Calcified tendinitis occurs most often in the supraspinatus tendon $(80 \%)$, then the infaspinatus tendon $(15 \%)$ and the tendon subscapularis $(5 \%){ }^{3}$ The clinical characteristics of this study were no different from previous studies, except for age. In this study, the age range was 55-70 years old, the age range was older compared to the previous rotator cuff tendinitis studies such as Loew et al (46 years) ${ }^{4}$, Haake et al (48.5 years), ${ }^{5}$ Perlick et al (48.4 years), ${ }^{6}$ Albert et al (46,6 years) ${ }^{7}$, but not much different from the research by $\mathrm{Hsu}$ et al (54.4 years) ${ }^{8}$ and Pan et al (55.2 years) ${ }^{4}$.

The etiology of calcified tendinitis is still controversial. Local tissue hypoxia and local stresses are cited as contributing factors.
Two different fundamental processes that lead to the formation of calcium deposits in the rotatorcuffthathave been erupted are degenerativecalcification and reactive calcification. Degeneration ofrotator cuff tendon fibers is usually associated with a wearand-tear effect and aging. The glenohumeral joint is the most commonly used universal joint in the body, and studies conducted in Sweden show that pressure and stress caused by work involving the arm may cause supraspinatus tendinitis. However, there is no evidence that a worker involved in heavy work involving the arm will cause calcified tendinitis over time, and Olsson suggests that the rotator cuff tendon of the dominant arm does not degenerate more than its contralateral arm.

Aging is considered the main cause of degeneration in the rotator cuff tendon. According to Brewer that with aging there is a decrease in supraspinatus tendon vascularization along with changes in muscle fibers. The most noticeable change relating to age is seen in fascicles, the collagen bundle which is the typical architecture of the tendon. Beginning in the late $40 \mathrm{~s}$ to $60 \mathrm{~s}$, most fascicles begin to deplete and fibrillation, which is defined as a degenerative process. The thinning fascicles show irregular cellular arrangement, and the fibers are fragmented. The volume of connective tissue carrying blood vessels between the fascicles may increase compared with the volume of the fascicles. In general supporters of the degenerative calcification theory fail to consider the age distribution, disease causes and 
morphological aspects of calcified tendinitis. The incidence of calcification increased with age in the case of degenerative calcification, whereas the incidence of calcine tendinitis peaked at the age of 50s. In addition, the degenerative process never shows the potential for self-healing. As well as histologically the features of degenerative calcification and calcification tendinitis are quite different.

\section{Pre calcification Phase}

At this stage where calcification predilection undergoes fibro cartilage changes, metaplasia of muscle cells (tenocytes) to chondrocytes is accompanied by meta chromatia, in collaboration with proteoglycans.

\section{Calcification Phase}

The calcification stage is divided into formative phase, rest phase, and resorptive phase. During the formative phase, the calcium crystals are stored mainly in the matrix vesicles, which combine to form a large focus of calcification. If the patient undergoes surgery during this stage, the deposit will look like a chalk picture and should be gouged out. In the resting phase, fibro collagen tissue borders the focus of calcification. The presence of this tissue shows the deposition of calcium in place is terminated. During the resorptive phase, after an inactive period that varies from disease process, resorptive calcium occurs by thin-walled blood vessels on the periphery of the deposit. Soon after, the deposit is surrounded by macrophages and nuclear giant cells that phagocytosis and eliminate calcium. If surgery is performed at this stage, the calcification looks soft and thick like a toothpaste.

\section{Post calsification Phase}

Along with calcium resorptive, the granulation tissue contains young fibroblasts and new blood vessels begin to overhaul the space previously occupied by calcium deposits. ${ }^{7}$ Although the pathogenesis of the calcification process can reasonably be established by looking at its morphology, it can not be determined what triggers the occurrence of fibro cartilage changes early in the process. Codman proposed tissue hypoxia as etiology because of the uniqueness of the supraspinatus tendon blood supply and shoulder mechanism. Nor do the factors that trigger the resorptive process are still unknown. ${ }^{1}$

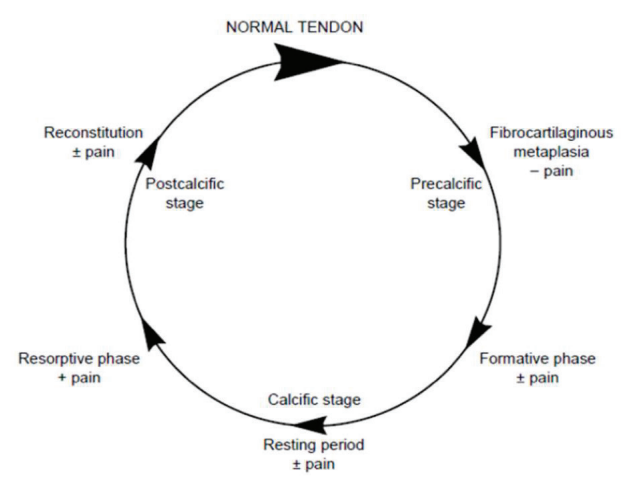

\section{Figure 1. Calcified stage scheme of calcified} tendinitis.

Uthoff et al agrees that the calcification process is actively mediated by cells in a proper environment, and that the formation of 
calcium deposits should be preceded resorptive. Therefore, Uthoff et al proposes that the evolution of the disease can be divided into three distinct phases, namely precalification, calcification, and postcalcification (Fig. 1). ${ }^{1}$

No significant correlations were found between calcium deposit size and pain intensity using VAS. This means that regardless of the size of the calcium deposit, will cause pain in the patient and the pain that arises is moderate pain, pain that must be managed. ${ }^{10}$ However, other things such as location of calcium deposits may be considered, whether the calcium deposit is located in the bursa is more painful than the calcium deposits located in the tendon fibers or vice versa. In Perlick's study, it was found that pain increased when the calcium deposit penetrated into the subacromial bursa. ${ }^{11}$ It may also be considered the form of calcium deposit, whether a calcium deposit that is scattered form like chalk (formative phase) is more painful than a calcium deposit that is firmly boundary and thick as having a resting period or vice versa. ${ }^{12}$ This certainly requires further research.

\section{CONCLUSION}

The size of the calcium deposit was not correlated with the pain intensity in rotator cuff calcified tendinitis patients. Regardless calcium deposit will cause pain, pain that arises is moderate pain and pain management must be handled properly. But further research is needed whether the location and form of calcium deposits affect the pain intensity in calcified tendinitis rotator cuff patients.

\section{REFERENCES}

1. Uhthoff, H.K., Loehr, J.W., Calcific tendinopathy of the rotator cuff: Pathogenesis, diagnosis, and management. Journal of American Academy Orthopaedy Surgery 1997;5:183-191

2. ElShewy MT. Calcific tendinitis of the rotator cuff. World Journal of Orthopedics. 2016;7(1):55-60. doi:10.5312/wjo.v7.i1.55.

3. Wang HT, Jung HK, Kyung LC, Hong KJ. Intramuscular calcification od the subscapularis muscle: Arthroscopy and orthopaedy sports medicine 2015;2(1);5559

4. Morgan GE, Mikhail MS, Murray MJ. Pain Management. th edition. New York : McGraw-Hill Medical.2013;359-361.

5. Loew M, Daecke W, Kusnierczak D, Rahmanzadeh M, Ewerbeck V. Shock-wave therapy is effective for chronic calcifying tendinitis of the shoulder. J Bone Joint Surg Br; 1999 81:863e7.

6. Haake M, Deike B, Thon A, Schmitt J. Exact focusing of extracorporeal shock wave therapy for calcifying tendinopathy. Clin Orthop Relat Res; 2002:323e31.

7. PerlickL, Luring C, Bathis H, Perlick C, Kraft C, Diedrich O. Efficacy of extracorporal shock-wave treatment for calcific tendinitis of the shoulder: experimental and clinical results. J Orthop Sci 2003;8:777e83.

8. Albert JD, Meadeb J, Guggenbuhl P, Marin F, Benkalfate T, Thomazeau H, et al. High 
energy extracorporeal shock-wave therapy for calcifying tendinitis of the rotator cuff: a randomised trial. J Bone Joint Surg Br 2007;89:335e41.

9. Burbank K.M, Stevenson J.H., Gregory R, Czarneck I, Dorfman J. Chronic Shoulder Pain: Part I. Evaluation and Diagnosis. J Am Fam Phy vol.77.2008:4;453-460

10. Pan PJ, Chou CL, Chiou HJ, Ma HL, Lee HC, Chan RC. Extracorporeal shock wave therapy for chronic calcific tendinitis of the shoulders: a functional and sonographic study. Arch Phys Med Rehabil 2003;84:988e93
11. Hsu CJ, Wang DY, Tseng KF, Fong YC, Hsu HC, Jim YF. Extracorporeal shock wave therapy for calcifying tendinitis of the shoulder. J Shoulder Elbow Surg 2008;17:55e9.

12. Cosentino, De Stefano, R., Selvi, E., Frati, E., Manca, S., Frediani, B., Marcolongo, R., Extracorporeal shock wave therapy for chronic tendinitis of the shoulder: single blind study. Ann Rheum Dis;2003 62:248250 . 